\title{
UN MECENAZGO FRONTERIZO: EL PROTECTOR DE INDIOS JUAN DE GÁNDARA Y LOS ÓPATAS DE OPODEPE (SONORA) A PRINCIPIOS DEL SIGLO XIX
}

\author{
POR \\ JOSÉ REFUGIO DE LA TORRE CURIEL \\ Departamento de Historia, Universidad de Guadalajara, México
}

\begin{abstract}
Este trabajo analiza las relaciones entre el protector de indios Juan de Gándara y los pueblos sonorenses ubicados bajo su protección. Para ello, dicha vinculación se entiende aqui como un efectivo mecanismo de reorganización social que permitió a los indios hacer frente a la desarticulación de sus comunidades en el contexto del colapso misional, al tiempo que se le sitúa como parte fundamental de la consolidación del capital político de nuevas élites regionales. A la larga, esta respuesta contribuiría de manera decisiva a la conformación de las facciones politicas que dominaron la escena sonorense de mediados del siglo XIX, cuya existencia no podría explicarse sin este tipo de alianzas.
\end{abstract}

Palabras Clave: Sonora, ópatas, protectores de indios, infidencia, tierras.

\section{INTRODUCCIÓN}

Conforme el siglo XVIII llegaba a su fin en las provincias del norte novohispano, la sociedad colonial vivía un proceso de recomposición que en el caso de Sonora encontraba en la desarticulación de las comunidades indígenas y en la consolidación de nuevas élites regionales dos de sus características principales.

Por una parte, el avance del poblamiento hispano, la conformación de nuevas haciendas y ranchos que demandaban mayor número de trabajadores, así como la creciente presión sobre la propiedad territorial minaban las estructuras básicas de las comunidades indígenas. En este contexto, mecanismos como el endeudamiento forzoso, los arrendamientos de tierras que terminaban con el despojo de sus antiguos propietarios, las invasiones de terrenos cuya posesión 
estaba en entredicho, y fenómenos como los ataques y las críticas a los regímenes misionales aceleraron este proceso de descomposición ${ }^{1}$. En contrapartida, durante el último tercio del siglo XVIII se consolidó en Sonora la presencia de una nueva generación de funcionarios, militares y colonos que llegaron alentados por la Corona para poblar y consolidar la intendencia de Arizpe. En el caso del norte y centro de Sonora, habría que citar las familias Elías González, Gándara, Aguilar, Escalante e Íñigo; otro tanto sucedía también en el sur de la provincia con los Almada, los Salido, una rama de los Gaxiola y los Quirós. Fortalecidos por sucesivas alianzas matrimoniales, familiares y económicas, estos prominentes miembros de la sociedad sonorense tomarían control de los rumbos de la vida local para principios del siglo XIX ${ }^{2}$.

Las complejas formas en que estos procesos estuvieron imbricados han comenzado a ser descubiertas en tiempos recientes mediante estudios que abordan la evolución de la propiedad territorial, las condiciones en que operaba el comercio local o las tendencias que afectaron a los conjuntos misionales del septentrión a fines del periodo colonial ${ }^{3}$. Con el objetivo de comprender desde otra perspectiva las formas de socialización e interdependencia arriba mencionadas, este trabajo analiza las relaciones entre el protector de indios Juan de Gándara y las comunidades ópatas ubicadas bajo su protección. Se parte del principio que, frente a los ataques a la vida corporativa de los indios, una estrategia que acercó a comunidades indígenas y a algunos miembros de los nuevos grupos de poder fue la búsqueda de mecenas y protectores poderosos por parte de la población indígena ${ }^{4}$. A la larga, esta respuesta contribuiría de manera decisiva a la conformación de las sociedades fronterizas de mediados del siglo XIX. En el caso particular de la familia Gándara, se encuentra aquí la explicación del ascendiente político y económico que algunos nacidos con ese apellido ejercerían sobre una amplia clientela política de extracción indígena durante buena parte del siglo decimonónico.

\footnotetext{
1 Vidargas, 1993: 440-441.

2 Vidargas, 1993: 444-446.

3 Radding, 1997: 171-215. De la Torre Curiel, LVIII/2 (México D.F., 2008): 595-656; 18/1 (Londres, 2009): 51-73.

4 Al lado, por supuesto, de otros mecanismos como la incorporación de los indios a las bandas de asaltantes, la fuga de los pueblos de misión o la búsqueda de empleos estacionales fuera de las misiones, los cuales no son abordados en profundidad en este trabajo. Sobre estos temas, véase, por ejemplo, Ortelli, 2007. De la Torre Curiel, 14 (Guadalajara, 2008): 11-31.
} 


\section{LOS ÓPATAS}

En el centro de Sonora, hacia el oriente del río San Miguel, alcanzando incluso la porción serrana de dicha provincia, se encontraba la Opatería, hogar de ópatas, eudeves y jovas; grupos indígenas emparentados entre sí étnica y lingüísticamente. Aunque era posible establecer pequeñas diferencias en el idioma y costumbres de dichos grupos, se les identificaba comúnmente con el nombre genérico de ópatas, si bien los otros dos nombres siguieron en uso de manera irregular durante el periodo colonial. En sentido estricto, este territorio no constituía una entidad compacta, ni era identificada por sus habitantes como un espacio étnico común, pues era posible distinguir las zonas de ocupación de cada uno de ellos por lo menos hasta mediados del siglo XVIII ${ }^{5}$. La afinidad lingüística de dichos grupos, así como el hecho de que, para principios del siglo XIX, jovas y eudeves parecen haber sido asimilados a otros grupos de población, han llevado a la práctica común de identificar el conjunto de este territorio como zona de ocupación ópata, llamándolo con el término genérico de Opatería 6 .

Según el jesuita Juan Nentuig, esta zona comprendía los pueblos de «Nátora, Arivetzi, Bacanora, Tonitzi, Soyopa, Nácori, Álamos, parte de Ures, Nacameri, Opodepe, Cucurpe hacia el poniente; desde aquí Arispe, Chinapa, Bacoatzi, Cuquiaratzi, hasta Babispe hacia el norte» ${ }^{7}$.

5 Carl Sauer únicamente menciona los jovas y los ópatas, arrancando aquí la tradición moderna de identificar a eudeves y ópatas como un sólo grupo. Sauer, 1935: 26-29. Hinton apoya esta postura, señalando a los eudeves como un subgrupo de los ópatas, únicamente diferenciados por pequeñas variaciones lingüísticas, en tanto que los jovas son considerados como «gente intermedia», «idénticos a los ópatas». Hinton, 1983: 320-322.

6 Algunos padrones son reveladores con respecto a la mezcla de jovas y eudeves con otros grupos. Por ejemplo, los padrones de 1803 y 1806 únicamente mencionan a ópatas, pimas y seris, residiendo en las misiones de la zona. Fray Ignacio Dávalos, Noticia de las misiones que ocupan los religiosos de la provincia de Xalisco... [en Sonora] hasta el año de 1802, Tecoripa, 18 de junio de 1803, Biblioteca Nacional (México), Fondo Franciscano (BNFF), 36/815; Fray Ignacio Dávalos, Noticia de las misiones que ocupan los religiosos... de la provincia de Xalisco [en Sonora] por los años de 1805 y 1806, Tecoripa, 29 de diciembre de 1806, BNFF, 37/829. Según Sauer, los jovas ya estaban en proceso de ser asimilados por los ópatas al tiempo de la llegada de los jesuitas. Sauer, 1935: 26. Cynthia Radding sugiere que la gradual desaparición de los jovas durante los últimos años del periodo colonial pudo deberse a varios factores: «Una pequeña minoría pudo haber tomado la identidad ópata; algunos pudieron haberse unido al grupo creciente de naborías y mestizos que trabajaban en las minas y las haciendas; otros incluso pudieron haber adoptado la vida nómada de los apaches». Radding, 1997: 150 (traducción propia).

7 Nentuig, 1977: 76, parágrafo 185. 
Distribución De Grupos ÉTNICOS En LA ProvinCia de Sonora haCia 1770

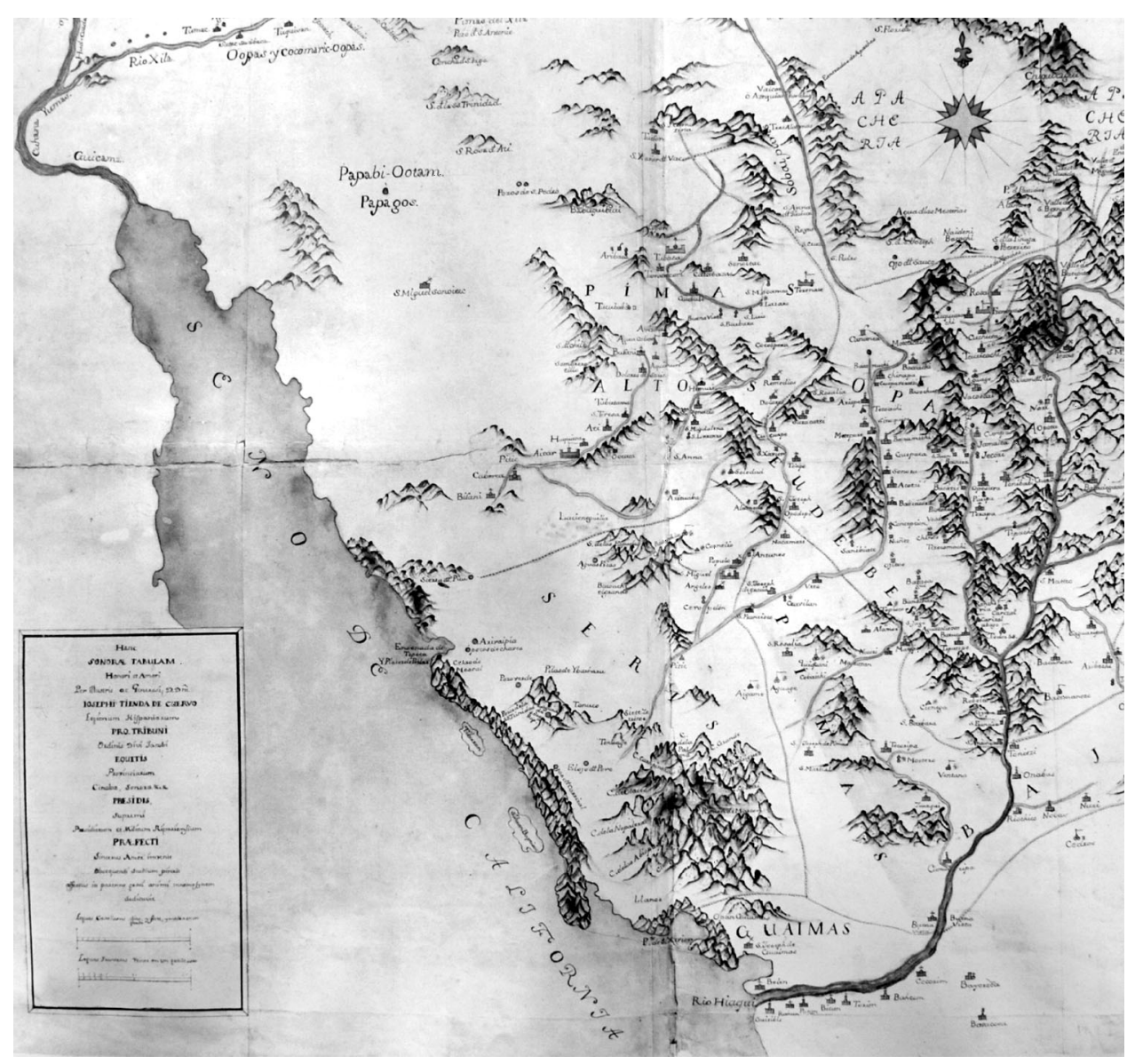

Fragmento de Sonorae Tabulam, ca. 1770, Museo Naval, Madrid, VIII-B-6.

A diferencia de otros grupos indígenas que habitaban la provincia de Sonora, los ópatas mostraron una rápida incorporación a la sociedad hispana, destacándose incluso como los mejores auxiliares en la defensa de aquellos territorios. De hecho, la notable huella que el mestizaje y los procesos de cambio cultural dejaban en este grupo para fines del siglo XVIII había motivado que, desde tempranas fechas, diferentes autoridades eclesiásticas y civiles propusieran dar por concluido el régimen misional entre los ópatas, como se puede ver en un comentario de 1774: «los indios dicen que son de nación eudeves y ópatas, pero a la verdad ellos son un revuelto y mixto de Españoles, 
mulatos, coyotes y otras castas [...], quieren ser indios para que el cura del partido no les pida y cobre sus derechos [...] pero no quieren ser mandados y gobernados como indios ni obedecer las correcciones y consejos del padre misionero» ${ }^{8}$.

Un rasgo de la personalidad de los ópatas, que cobra gran significado en este trabajo, es la importancia que para la vida diaria de este grupo tenía el sentido de la reciprocidad. Contra la imagen que el testimonio arriba citado pudiera sugerir, la aparente falta de sumisión de los ópatas procedía más bien de un alto sentido de su contribución hacia la sociedad hispana. De hecho, en la memoria histórica de los ópatas estaba presente la alianza que habían establecido con los españoles desde los primeros contactos, y celebraban dicho momento mediante el dagüinemaca, danza con que se recordaba el día en que habían comenzado a fraternizar con los españoles. Al tiempo que se recordaba el sentido histórico de este vínculo, el dagüinemaca celebraba la congruencia que dicho pacto tenía con los valores propios de la sociedad ópata. Literalmente, el nombre del baile significa en español «dame y te daré», y en su ejecución las virtudes ensalzadas eran la asistencia mutua, la solidaridad, la amistad y la gratitud. De acuerdo al testimonio de un observador del siglo XIX,

en este baile se acostumbra que hombres y mujeres bailen a la persona por quien se sienten con inclinación. Toman el signo de algún obsequio (como de un caballo, vaca, pollos, etcétera) y abrazan a la persona agraciada, obligándola a que dé una o dos vueltas al compás del canto, con lo que queda concluido un tratado de alianza y amistad entre ambas personas que no lo relaja sino la muerte. Estos se llaman noraguas, es decir, amigos; pero son tan sinceros y buenos, que el indio deja a sus hijos y a su mujer por su noragua cuando sabe que emprende una caminata peligrosa o que pude prestarle algún servicio 9 .

Junto con este baile, los ópatas conservaban todavía a principios del siglo XIX otra danza de carácter histórico mediante la cual recordaban, al decir del mismo testigo, «el tránsito de los aztecas y la venida de Moctezuma, a quien esperan como los judíos a otro Mesías» ${ }^{10}$. El jojo, nombre con que esta danza era conocida, vinculaba de esta forma las tradiciones orales de los ópatas con la esperanza de un futuro más prometedor, si no en el sentido mesiánico entendido por Ignacio Zúñiga en 1835, sí con la ilusión de contar entre sus

${ }^{8}$ Fray Antonio de los Reyes, Memorial y Estado Actual de las Misiones de la Pimería alta y Baja, México, 6 de julio de 1774, Archivo General de Indias, Sevilla (AGI), Guadalajara, legajo 586.

9 Zúñiga, 1835: 4, nota 2.

10 Zúñiga, 1835: 7, nota 6. 
filas con un individuo que pudiera reivindicar la primacía de los ópatas y ganar para sus compatriotas un mejor lugar en la sociedad hispana ${ }^{11}$.

Se estima que, poco después de 1850 , las distintas variantes de la lengua ópata habían desaparecido; el siglo XIX, al decir de un etnógrafo contemporáneo, «vio la desaparición de la cultura ópata y la asimilación de dicho grupo»a otros sectores de la población ${ }^{12}$.

\section{UN GRANADINO EN SONORA}

Son pocos los datos con que contamos para reconstruir los derroteros que situaron a Juan de Gándara en el noroeste novohispano, y son más escasas aún las noticias sobre sus primeros años de vida. Sabemos, en cambio, gracias a un proceso judicial realizado en 1818, que era natural del reino de Granada y que había nacido hacia $1768^{13}$.

Para 1802 se encontraba en el real de Aigame, desempeñándose como comisionado de minería ${ }^{14}$; eventualmente su actividad minera le permitiría avecindarse en Ures, población que constituiría el núcleo de las empresas agroganaderas que sostendrían a su descendencia a partir de la hacienda de Santa Rita. Al igual que otros hacendados de su época, Juan de Gándara también tendría la oportunidad de actuar como abastecedor de distintos artículos de

11 La importancia de estos reclamos, así como la esperanza de los ópatas en la venida de este personaje, se harían patentes en las sublevaciones de 1819 y 1824 , y en los demás alzamientos que siguieron a la política de los gobiernos estatales sobre privatización y reparto de tierras comunales mediante las leyes 88 y 89 de 1828. La creciente presión por la propiedad territorial llevó en dichas ocasiones a los ópatas a intentar sustraerse al control del gobierno estatal y a proponer la creación de gobiernos autónomos que reconocieran los privilegios con que habían contado los ópatas durante el periodo colonial. Vidargas, 1993: 453.

12 Hinton, 1983: 321 (traducción propia).

13 Efectivamente, en un proceso judicial de 1818 declaraba el propio Gándara sobre su lugar de procedencia, afirmando que para esas fechas tenía cincuenta años de edad. Diligencias practicadas a consecuencia de representación del Teniente de Justicia de Cucurpe sobre que los indios de Opodepe habian provisión extraordinaria de arcos y flechas, Archivo de la Real Audiencia de Guadalajara, Guadalajara, México (ARAG), Ramo Civil, 427-11-6947, ff. 38-39. La declaración de Gándara sobre su procedencia resulta en cierta medida intrigante, pues los orígenes de su apellido se ubican en los reinos del norte de la Península Ibérica, específicamente entre Cantabria y Galicia. Véase, por ejemplo, el Expediente de solicitud de licencia de embarque de Juan de la Gándara Pedrajo, natural de la ciudad de Santander, 2 de mayo de 1795, AGI, México, legajo 2496, n. ${ }^{\circ} 101$.

${ }^{14}$ El teniente general de subdelegado del real de Aigame contra Franciso Paz por homicidio de José Miguel Albiso, 1802, ARAG, Ramo Criminal, 49-2-762, f. 15. Archivo General de la Nación, México D. F. (AGN), Indios, volumen 100, f. 483. 
consumo para los presidios del norte novohispano, aunque al parecer no se abocó sistemáticamente a este negocio ${ }^{15}$.

Es probable que su labor en la promoción de la minería le hubiera merecido ser tenido en cuenta para ocupar el cargo de protector partidario de indios en 1805, tras la petición que en este sentido hiciera el Comandante General de las Provincias Internas, alegando la necesidad que había en Sonora de estas personas ${ }^{16}$. Así las cosas, en la víspera del movimiento insurgente, Juan de Gándara reunía en torno a su persona una pequeña heredad, una creciente visibilidad política y un incipiente influjo sobre las comunidades ópatas y pimas del partido de Arispe.

El paso de Juan de Gándara por el real de Aigame no estuvo exento de acusaciones en su contra. Aprovechando su posición de privilegio, recordaba años más tarde uno de sus adversarios políticos, dicho personaje «se abrogó las funciones del juez real, por cuyo atentado lo despojaron con sonrojo y se expidió una circular por el gobierno de Arispe a todas las subdelegaciones de la provincia para que en lo sucesivo no tuviese este empleo, ni otro» ${ }^{17}$. Las relaciones que por esa misma época entablaban Gándara y el intendente interino Fernando Roxo eran motivo suficiente para que en Sonora circularan rumores de que «desde los Ures iban dictadas las providencias y decretos por Gándara»" ${ }^{18}$.

Si bien tales acusaciones parecían exagerar el alcance real de la voluntad de este sujeto, lo cierto es que indicaban que paulatinamente Gándara se convertía en un actor de importancia en el ámbito local. El control de los cargos de gobierno en el entorno inmediato constituía un mecanismo convencional para la supervivencia de estos liderazgos en ciernes y el caso que aquí nos ocupa no fue la excepción. En particular, el contexto de la promulgación de la Constitución de Cádiz de 1812 en los reinos americanos, así como la respectiva jura de dicha carta y la elección de ayuntamientos constitucionales en So-

15 Cuentas de Juan de Gándara como abastecedor de Jabón a presidios de las provincias internas, 16 de noviembre de 1816, AGN, Indiferente Virreinal, Sección Real Hacienda, caja 4428, exp. 19. Según esta fuente, los envíos de jabón en ese año tuvieron un importe de 3.960 pesos de acuerdo a la siguiente distribución: Janos (488 pesos, 2 reales, 2 granos); San Buenaventura (429 pesos, 3 reales, 6 granos); Carrizal ( 784 pesos, 5 reales, 6 2/3 granos); San Eleazario (780 pesos, 1 real, 10 2/3 granos); Segunda Compañía Volante (972 pesos, 1 real, 4 2/3 granos) y El Paso (505 pesos, 5 reales, $62 / 3$ granos).

16 Solicitud del Comandante General de Provincias Internas ante la Real Audiencia de Guadalajara para que se nombren protectores de indios en Sonora, 1805, ARAG, Ramo Criminal, 64-19-1035.

17 Anónimo sobre excesos del protector de indios Juan de Gándara, 1819, AGN, Indios, volumen 100, f. 483.

18 Idem. 
nora, brindaron a la iniciativa de sujetos como Gándara la oportunidad de capitalizar su ascendiente social y político ${ }^{19}$.

Como se recordará, el texto constitucional de 1812 establecía la posibilidad de formar ayuntamientos en aquellas poblaciones que contaran con quinientos habitantes ${ }^{20}$. Aunque tal prerrogativa no debía entenderse como una atribución unilateral y automática, sino que debía realizarse en sintonía con las autoridades provinciales, villas como Ures (donde Juan de Gándara estaba avecindado) exigieron de inmediato este derecho tan pronto se publicó la Constitución en la cercana capital sonorense de Arispe ${ }^{21}$. Al frente de estas demandas se encontraba el propio Juan de Gándara, quien por todos los medios buscaba que el subdelegado de aquel partido acudiera a Ures para jurar fidelidad a la Constitución y realizar las elecciones municipales. Parte del argumento empleado por Gándara y el misionero local para convencer al subdelegado de la obligación que tenía de presentar dicho documento en Ures era que en aquella villa se hallaban congregadas «las dos mil almas poco más o menos que contiene este vecindario, inclusas como setecientas de naturales» ${ }^{22}$.

Tras una incierta actitud inicial por parte del subdelegado, finalmente la villa de Ures presenció la proclamación y jura del texto constitucional con la asistencia del subdelegado Rafael Ortiz de la Torre el 6 de febrero de 1814. El protocolo requería el nombramiento de un secretario para la elaboración de las

19 En diversas ocasiones, Antonio Annino ha explicado este proceso de consolidación del poder de nuevos grupos: «La difusión de la representación liberal en las zonas rurales ofreció nuevas oportunidades de ascenso social y político a numerosos grupos, desde los blancos intermedios, en el pasado subalternos del patriciado de las ciudades importantes, a los nuevos y antiguos principales indios, que gracias a las elecciones pudieron consolidar sus posiciones jerárquicas». Annino, 1994: 247. Esta misma tesis es retomada y ampliada por Annino, relacionándola con las autonomías territoriales en 1995a; 1995b: 63. Al igual que Annino, Antonio Escobar ve en la erección de nuevos ayuntamientos, a partir de 1812, un hecho que afectó a corto y largo plazo tanto la estructura política como territorial de los pueblos de indios, y coincide en que este fenómeno se tradujo en el crecimiento y consolidación de las élites locales. Sin embargo, a pesar de que nuevos grupos se apropian del poder político, este «siguió concibiéndose como concentrado y unificado, y en ocasiones no compartido», lo que representaba importantes continuidades con respecto a épocas anteriores. Escobar Ohmstede, 1997: 295-301.

20 Se permitía la participación de los indios y quedaba señalada la exclusión de los negros para estos fines. Annino, 1994: 244. Sobre los contextos e implicaciones de esta apertura, véase De Castro, 1979. Romanelli, 1997. Guedea, 1994.

21 La Constitución había sido publicada en Arispe el 28 de noviembre de 1813. Oficio firmado por Juan de Gándara, San Miguel de Ures, 3 de abril de 1814, AGI, Guadalajara, legajo 297.

22 Carta de fray Martín Pérez y Juan de Gándara al subdelegado Don Rafael Ortiz de la Torre, Ures, 24 de enero de 1814, AGI, Guadalajara, legajo 297. 
actas y la toma del juramento, recayendo dicha responsabilidad en Juan de Gándara. Así correspondió a este último personaje convocar a «todos los vecinos y residentes en este pueblo, sin distinción de clases ni castas [así como a] los justicias legítimamente reconocidos en este suelo», para comparecer delante del subdelegado Rafael Ortiz de la Torre y su lugarteniente Juan José Salcido y proceder a la toma de juramento:

... al frente de un altar que se mandó poner en las casas reales delante de una Imagen de Jesucristo y los Santos Evangelios, les tomé y recibí juramento en esta forma: ¿juráis por Dios y por los Stos Evangelios guardar y hacer guardar la Constitución política de la Monarquía Española, sancionada por las Cortes generales y Extraordinarias de la Nación, y ser fieles al Rey?, respondieron. Sí juro. Luego tomó el subdelegado como Presidente el Estandarte en donde iba colocada la Constitución para satisfacción del público, y en forma de procesión, y repique de campanas con el acompañamiento más condecorado y decente que ofrece el país, se trasladó a la Iglesia parroquial en cuya puerta mayor se hallaba el Rdo. Párroco con capa, cruz y ciriales, y habiendo recibido de mano del presidente el citado Estandarte, en el mismo orden de Procesión lo llevó por el cuerpo de la Iglesia y lo colocó en la altar mayor al lado del Evangelio, y se dio principio a la Misa. Concluido el Evangelio, leí la constitución en el Paraje más público y visible del templo, y luego que concluí y coloqué en el Estandarte: El Rdo Padre Fr. Francisco Robles, como designado por el mismo Párroco al efecto, subió al púlpito, y allí hizo una breve e inteligible exhortación análoga al asunto que acababa de leerse. Prosiguió la misa, y acabada el Rdo. Párroco con capa, cruz y ciriales, se puso en la altar portátil, que estaba en el cuerpo de la iglesia, junto a las gradas del presbiterio, y ante una imagen de Jesucristo y los santos Evangelios, junto con el Pueblo, y sin preferencia alguna [...], prestaron el juramento en presencia del subdelegado ${ }^{23}$.

El ceremonial del 6 de febrero en Ures constituía un simbólico despliegue de lealtad hacia la Corona española y las autoridades constituidas. Al mismo tiempo, los papeles desempeñados por los distintos participantes reforzaban la estratificación social vigente en el interior de la comunidad. Sin embargo, en esta ocasión festiva había un caso en particular cuya participación representaba un proceso diferente; usando una metáfora de Peter Burke, podría afirmarse que, mediante su protagonismo en este ceremonial, el secretario de actas de la jura contribuía para «fabricar» un Juan de Gándara políticamente mucho más visible y complejo ${ }^{24}$.

23 Actas de la jura de la Constitución de 1812 en la villa de San Miguel de Ures, 6 de febrero de 1814, AGI, Guadalajara, legajo 297. Énfasis en el original.

24 «Decidí hablar de la fabricación de Luis XIV en lugar de la fabricación de su imagen [...] para poner de relieve que el rey se creaba o recreaba continuamente mediante las actuaciones en las que representaba su papel; el "gran papel", como lo llamaba un historiador sueco en un trabajo sobre el rey Gustavo III. Las actuaciones y las múltiples representaciones 
Otro mecanismo igualmente efectivo para sancionar la formalización de la influencia de Juan de Gándara entre el vecindario de Ures se presentaría a la mañana siguiente, el 7 de febrero, cuando se reunió en las casas reales de aquel pueblo una asamblea organizada por Juan de Gándara, el misionero fray Martín Pérez, el justicia Juan José Salcido y el gobernador indígena Domingo Ortega. El objetivo era seleccionar, de entre «todos los ciudadanos domiciliados en esta parroquia», a nueve electores en quienes se confiaría el nombramiento de las autoridades municipales de Ures. Los cuatro organizadores presentaron al subdelegado una lista de 39 españoles y 38 indios; dicha nómina, argumentaban los sujetos mencionados, reunía a todos aquellos que cumplían los requisitos para sufragar en tal ocasión. Previniendo que alguien desafiara su criterio, momentos antes de la elección, el propio Gándara había advertido a la concurrencia a la entrada de las casas reales: «No se evita la entrada, al que por olvido no haya sido llamado, siempre que se presente haciendo ver goza de los derechos de ciudadano» ${ }^{25}$. Nadie pudo argumentar que estaba excluido de la asamblea y, al margen de un incidente por el orden en que fueron llamados algunos votantes, el resultado confirmó como electores a Juan de Gándara y a ocho vecinos cercanos a su persona (entre los que destacaba el comerciante Ramón Agudo, más tarde acusado de ser partícipe de una causa de infidencia junto con Gándara).

En este contexto, el establecimiento del ayuntamiento constitucional de Ures el 8 de febrero de 1814 transcurrió tranquilamente. Los electores locales no demoraron en nombrar a Juan de Gándara como «alcalde constitucional y presidente del ilustre Ayuntamiento»; Javier Salcido, Pedro Martínez, Ignacio Salcido y el indio Juan López fueron nombrados regidores, en tanto que el cargo de síndico procurador del común recayó en Pedro Cosío.

A partir de entonces, y con la autorización del subdelegado del partido de Orcasitas, Juan de Gándara comenzó a presentarse ante la población local y ante diferentes instancias de gobierno (incluido el intendente de Sonora, Ignacio Bustamante) como alcalde constitucional de Ures. En principio, las atribuciones de Gándara no fueron disputadas por dichas autoridades superiores, aun cuando la confirmación de su cargo por parte del intendente gobernador no había sido dada a conocer. De hecho, el propio intendente reconocía de manera implícita la legitimidad del cargo de Gándara al fir-

de dichas actuaciones (representaciones de representaciones) volvieron visible a Luis para diferentes públicos: para sus nobles, para su pueblo, para las cortes extranjeras e incluso para la posteridad». Burke, 2006: 111.

25 Acta de la Junta de los ciudadanos de Ures para nombrar electores, 7 de febrero de 1814, AGI, Guadalajara, legajo 297. 
mar un oficio dándole el tratamiento de «Señor Alcalde Constitucional de Ures $»^{26}$.

Sin embargo, en un vuelco desfavorable para la causa gandarista, a poco menos de dos semanas de celebradas las elecciones en Ures, el intendente de Sonora haría saber al subdelegado de Orcasitas y al propio Juan de Gándara que desaprobaba tanto las actas de la elección como la existencia de aquel ayuntamiento en tanto no se formara la Diputación Provincial que debía disponer la creación de dichos cuerpos ${ }^{27}$. Esta actitud de Bustamante contrastaba con la alegada capacidad de Gándara para influir en el ánimo de uno de los predecesores del intendente, como se ha visto líneas arriba; es probable que más que cuidar las formas, lo que buscaba el intendente era poner límites a la promoción política de nuevos personajes en aquellas partes de la provincia de Sonora. En este sentido se entendería el hecho de que el intendente sí hubiera aprobado las actas y las elecciones celebradas por las mismas fechas en Arispe y Nacameri, al tiempo que rechazaba la creación de los ayuntamientos de Ures, Oposura y otros pueblos del valle de Sonora.

A pesar de que el gobernador hubiera desconocido la existencia de la corporación municipal de Ures, el ayuntamiento presidido por Gándara decidió pronunciarse en contra de esta determinación y seguir operando en el nivel local por suponerse «en el goce de sus derechos... [por lo que] continúa en ellos legalmente». Más aún, el propio Gándara declaraba que a ese ilustre cuerpo le era imposible «desistir [...] en el ejercicio de sus funciones por una simple insinuación $»^{28}$.

Ya para estas fechas, la influencia local de Juan de Gándara era perceptible en diversos círculos de la vida política sonorense. Aunque aún hoy día es difícil corroborar su afirmación en el sentido de que contaba con el apoyo de «más de cuarenta mil indios» que gozaban de su protección, lo cierto es que sus contemporáneos no decidieron entrar a esta fase de averiguaciones y concedieron un relativo margen de maniobra para la sociedad establecida entre Gándara y las comunidades indígenas de los ríos San Miguel y Sonora. Como se verá a continuación, dicha relación tuvo en la figura jurídica del protector

26 Oficio del Intendente Ignacio Bustamante al Alcalde Constitucional de Ures Juan de Gándara, Arispe, 17 de febrero de 1814, AGI, Guadalajara, legajo 297.

27 Este es el contexto de las siguientes comunicaciones, agrupadas en el mismo expediente: Ignacio Bustamante, intendente de Sonora, a Juan de Gándara, Arispe, 17 de febrero de 1814; Ignacio Bustamante a Rafael Ortiz de la Torre, Arispe, 17 de febrero de 1814; Rafael Ortiz de la Torre a Juan de Gándara, El ranchito, 20 de febrero de 1814; Oficio firmado por Juan de Gándara, San Miguel de Ures, 3 de abril de 1814, AGI, Guadalajara, legajo 297.

28 Juan de Gándara al subdelegado de Orcasitas, Rafael Ortiz de la Torre, Ures, 29 de febrero de 1814, AGI, Guadalajara, legajo 297. 
partidario un núcleo vertebrador cuya influencia trascendería incluso el periodo vital del patriarca de la familia Gándara ${ }^{29}$.

\section{EL PROTECTOR PARTIDARIO Y LA FORMACIÓN DE NUEVAS ALIANZAS EN LA FRONTERA}

Para los habitantes de la Opatería, lo mismo que para otros grupos del norte de la Nueva España, la reciprocidad en su trato con los españoles era parte fundamental de su decisión de convivir y trabajar tanto dentro del régimen misional como en los ranchos y reales mineros. Minada la capacidad de los religiosos de la provincia de Xalisco para contribuir al bienestar de los pueblos de misión de la Opatería y la Pimería baja, debido a las limitaciones legales impuestas a su administración desde tempranas fechas, los habitantes de dichas misiones encontraron en algunos españoles prominentes las figuras que habrían de brindar a sus pueblos cierto grado de seguridad ocupacional y alimenticia.

En el contexto de los pueblos de indios del norte novohispano, este proceso se vio favorecido, a fines del periodo colonial, por la designación de los llamados jueces protectores o protectores partidarios de indios, figura creada a principios del siglo XVI con el propósito de conferirle la representación legal de las comunidades indígenas en los litigios que tuvieran que seguir ante los tribunales o las autoridades españolas ${ }^{30}$.

29 Sin este capital político no podría entenderse, por ejemplo, el apoyo que los posteriores jefes militares y eventuales gobernadores del estado de Sonora Juan Bautista Gándara y, sobre todo, Manuel María Gándara, encontrarían en esta zona durante el siglo XIX, por lo menos hasta la derrota de las fuerzas imperialistas en aquel estado hacia fines de la década de 1860. A la fecha, los mejores estudios sobre la conformación y evolución de esta figura siguen siendo Bayle, 1945; Cutter, 1986; Suñe Blanco, 2005.

30 El oficio de protector de indios data de 1529; su creación tuvo como contexto el exterminio de los indios del Perú por los abusos de los encomenderos locales, frente a lo cual, la Corona nombró a Fernando de Luque como «protector y defensor de ellos [los indios de Túmbez y sus provincias] así para el buen tratamiento, como para que mirase en su conversión lo que más convenía y cuidase de su conservación y que nadie les agraviase». El oficio fue posteriormente suprimido en 1582. Sin embargo, por real cédula de Felipe II, dada en Madrid el 10 de enero de 1589 (Ley I, título VI, libro VI de la Recopilación de leyes de Indias), se ordenaba que los virreyes y presidentes gobernadores procedieran nuevamente al nombramiento de protectores «y que estos sean personas de edad competente, y ejerzan sus oficios con la cristiandad, limpieza y puntualidad que son obligados, pues han de amparar y defender a los indios». Asimismo, esta cédula disponía que, en donde hubiere audiencia, se contara con un abogado y procurador de indios. Posteriores cédulas reales modificaron la forma en que debían nombrarse los protectores y prevenirse sus abusos; para 1781, una nueva cédula real establecía que los 
Para los fines de este trabajo es importante destacar que los protectores debían circunscribirse a sus funciones de representantes legales ${ }^{31}$, lo cual no incluía jurisdicción ni facultad judicial alguna, como más adelante se comentará. Es asimismo necesario considerar que, por lo que hace al norte novohispano en el atardecer del siglo XVIII, la iniciativa de contar con dichos representantes estaba impulsada por los planes que desde la comandancia general de las Provincias Internas se gestaban para reformar el manejo de los bienes comunales y el control que los misioneros tenían sobre la mano de obra indígena. Así, el lenguaje empleado por los encargados de esta dependencia trataba de presentar la necesidad de contar con protectores como una medida benéfica para los indios «a fin de que no volviese a oprimírseles con los servicios personales y otros gravámenes abusivos». Según el comandante Pedro de Nava, tal era el espíritu que en 1790 había animado a Jacobo Ugarte y Loyola, a la sazón titular de la comandancia, para solicitar que la audiencia de México nombrara protectores para las provincias norteñas. Esa misma urgencia, decía Nava en 1796, era la que le llevaba a pedir al Consejo de Indias que se nombraran dichos protectores, indispensables para prevenir las vejaciones y maltratos de que pudieran ser objeto los indios en el contexto de las libertades que la abolición del «antiguo método de comunidad» les ofrecería ${ }^{32}$.

protectores no podrían cobrar sueldo alguno por su trabajo en favor de los indios. Ayala, 1995: 83-89. León Pinelo y Solórzano Pereyra, 1791: 242.

En teoría, distintos tribunales entendieron que el oficio habría cesado con la independencia de México al declararse la igualdad de todos los ciudadanos de la república. Un ejemplo de lo anterior puede verse en el caso del protector partidario de indios de la provincia del Nuevo México, don Ignacio María Sánchez Vergara, destituido de su cargo con tal argumento por el gobierno local en 1821 y reinstalado nuevamente por la Audiencia de Guadalajara. ARAG, Ramo Civil, 435-19-7117. En el estado de Sonora, los protectores fueron restablecidos mediante el decreto 61 de 10 de junio 1835 con el fin de que dirigieran a los indígenas «en todos los asuntos civiles que ocurran». Decreto número 61 del gobierno del Estado de Sonora, Arispe, 11 de junio de 1835, The Bancroft Library (BL), M-M 285: 409. Un ejemplo de la aplicación de este decreto en Sonora se encuentra en la actuación de Rafael Elías González como protector de indios de los pueblos de Sinoquipe, Banamichi, Huepaca, Aconchi y Baviácora en el reparto de tierras comunales en 1836. Archivo General del Estado de Sonora (AGES), Fondo Ejecutivo, tomo 84, exp. 9.

31 Aunque Suñe Blanco indica que «los protectores de indios en la frontera norte tenían una responsabilidad más allá de la simple representación legal», a final de cuentas sus funciones se circunscribían a ese mismo rubro, como ella misma lo reconoce: «Se denominaron, generalmente, "capitanes protectores" y eran hombres avezados en la guerra. Su misión era la defensa de los indios en procedimientos judiciales, vigilar que no se dañaran sus derechos sobre tierras y aguas así como abastecerlos en su alimentación, ropa y herramienta y hasta en juegos y libros por su adoctrinamiento». Suñe Blanco, 2005: 736-737.

32 Informe de Pedro de Nava al Consejo de Indias, Chihuahua, 5 de enero de 1796, AGI, Guadalajara, legajo 586, f. 500. Sobre las reformas en la vida comunal de las misiones, véase el 
En cuanto a la provincia de Sonora en específico, parece que este tardío resurgimiento de los protectores de indios tuvo como detonante una solicitud que en los mismos términos dirigiera el comandante general, Nemesio Salcedo, ante la audiencia de Guadalajara en $1805^{33}$. En respuesta, la audiencia nombró tres protectores para igual número de partidos, encargando a Juan de Gándara la representación de los indios del partido de Sonora que agrupaba varias poblaciones de los ríos Yaqui y Sonora (Nacameri, Opodepe, Ures, Santa Rosalía, San José de Pimas, Cumuripa, Tecoripa, Suaqui, Mátape, Nacori, Cocorit, Bacum, Torim, Vicam, Potam, Raum, Huirivis y Belem) ${ }^{34}$.

Sin lugar a dudas, este nombramiento permitió que las actividades productivas de Gándara, basadas en el comercio entre Guaymas y las poblaciones del somontano sonorense cercanas a Ures, así como en la explotación de su hacienda de Santa Rita, se vieran favorecidas con el concurso de los ópatas, pimas y yaquis residentes en esta zona. En este sentido, quienes se mostrarían más activos en este vínculo serían los ópatas, de quienes eventualmente el subdelegado de Sonora llegaría a decir en 1819 que habían perdido su tradicional fidelidad a la Corona porque «no reconocen más superior que a su protector Don Juan de Gándara» ${ }^{35}$.

decreto del propio comandante Pedro de Nava, fechado en Chihuahua el 10 de abril de 1794, en AGI, Guadalajara, legajo 586, ff. 494-499.

33 Solicitud del Comandante General de Provincias Internas ante la Real Audiencia de Guadalajara para que se nombren protectores de indios en Sonora, 1805, ARAG, Ramo Criminal, 64-19-1035. Por regla general, las distintas instancias gubernativas y judiciales buscaban que dicha disposición se acatara para separar a los eclesiásticos de los asuntos de los pueblos y para evitar el problema de tratar directamente con crecidas comitivas de indios. Un ejemplo de esta actitud se puede ver en la resolución del litigio por tierras sostenido por los indios de Opodepe contra los de Tuape en 1818, para la cual, el asesor de la intendencia de Sonora insistía en que el nuevo reparto de tierras de los pueblos debía hacerse «con asistencia de los protectores y no los reverendos padres ministros doctrineros ni los indios por sí solos». ARAG, Ramo Civil, 424-1-6888, f. 70.

34 Los otros dos partidos eran Arispe (con los pueblos de Arispe, Oposura, Cucurpe, Batuco, Bacerac, Guachinera, Guásavas, Bacadeguachi, Óputo, Chínapa, Sinoquipe, Banámichi, Guépaca, Aconchi, Babiacora, Cucurpe, Tuape, Babispe, Cuquiarachi, Bacoachi, Caborca, Atil, Tubutama, Saric, San Xavier del Bac, Tumacacori, Cocóspera, San Ignacio, Tubac, Tucson y Santa María Soamca) y Álamos (Batacosa, Tepagui, Conicari, Macoyagui, Nuri, Maicoba, Yécora, Movas, Ónavas, Tónichi, Arivechi, Bacanora, Pónida, Saguaripa, Santo Tomás, Taraichi, Camoa, Navojoa, Cuiximpo, Hechojoa, Tagueria, Santa Cruz, Baimena, Chois, Huiris, Baca, Toro, Charay, San Miguel, Mochicague y Ahume). Solicitud del Comandante General de Provincias Internas ante la Real Audiencia de Guadalajara para que se nombren protectores de indios en Sonora, 1805, ARAG, Ramo Criminal, 64-19-1035.

35 Denuncia del pueblo de Opodepe contra fray Luis Romero por injurias y malos tratos, 1819, ARAG, Ramo Criminal, 147-11-2227, f. 19. La frase textual fue tomada del testimonio de Ramón Carpena, subdelegado de Sonora. 
Aunque desafortunadamente la importancia de Gándara para los pueblos de la zona no ha podido ser cuantificada en términos del número de peones o de la producción agrícola y ganadera de sus ranchos, hay distintos testimonios que reflejan la forma en que los indios sabían aprovechar la protectoría para su beneficio, al tiempo que también hablan de la creciente inconformidad de distintos vecinos en contra de Gándara, así como del interés de ciertos españoles, misioneros e indios por mantenerse en buenos términos con este procurador. Uno de tales ejemplos se encuentra en el esfuerzo coordinado del misionero de Opodepe, fray Luis Romero, el comerciante Ramón Agudo y los indios del propio pueblo para fabricar arcos y lanzas y llevarlos hasta la hacienda de Santa Rita para regalárselos a don Juan de Gándara en 1818 con el fin de ayudar en la protección de dicha hacienda frente a la amenaza de los indios seris. El gesto, diría un observador de la época, obedecía a que los de Opodepe «querían como protector de aquel pueblo hacerle algún servicio» a Gándara ${ }^{36}$.

Para otros habitantes de Sonora, este creciente influjo tenía tintes abiertamente nocivos para el funcionamiento de aquella sociedad. Durante los años finales del periodo colonial, las denuncias en contra de la presencia de los protectores de indios estuvieron asociadas a diferentes cargos de abusos, excesos y vejaciones por parte de los protectores en contra de sus propios representados; sin embargo, en el periodo de la guerra de la independencia en particular, tal retórica sumaría también el argumento de la inestabilidad social y el riesgo de la violencia y el levantamiento en contra del gobierno como consecuencia de la perniciosa influencia de estos personajes. Una denuncia anónima dirigida al virrey Juan Ruiz de Apodaca en febrero de 1819 daba cuenta de estos sentimientos al narrar el lamentable estado al que parecía precipitarse la provincia de Sonora por culpa de Juan de Gándara. Según se le hiciera saber al virrey, dicha acusación solicitaba la remoción de Gándara por los perjuicios que ocasionaba a los sonorenses, toda vez que:

... se dice que Don Juan de Gándara, protector de indios ha corrompido de tal modo con su protección las costumbres de dichos indios [de Sonora] en perjuicio de los españoles y del mismo país que ya no trabajan sino cuando se hallan en extrema necesidad, no sacando de las minas y las Haciendas sino una cantidad infinitamente menor que la que se sacaba en tiempos anteriores; y hallándose una porción de estos indios entregados a toda clase de vicios, amenazan a los españoles con su protector, siendo apoyados por él aunque no tengan razón; que desobedecen a los justicias y causan muchos perjuicios a los vecinos ${ }^{37}$.

36 ARAG, Ramo Civil, 427-11-6947.

37 Anónimo contra Juan de Gándara por corromper a los indios de Sonora, 1819, AGN, Tierras, volumen 100, f. 476. 
El anónimo posiblemente era producto de la pluma de fray Luis Romero (misionero de Opodepe, recientemente enemistado con Juan de Gándara) ${ }^{38}$, o quizá también pudiera atribuirse su autoría al subdelegado de Sonora, Ramón Carpena, quien de manera pública había afirmado que los ópatas de Opodepe no reconocían más autoridad que la de Juan de Gándara. Este argumento también aparece en el anónimo contra Gándara, usado en el mismo contexto de la estrecha sociedad de los opodepetanos y su protector, aunque, al mismo tiempo, hace extensivo el agravio de los indios contra el misionero local:

en junta formal que hizo [el subdelegado Carpena] acompañado de su padre ministro [Romero]... resultó el que a las claras con el mayor escándalo no solo le faltaron al respeto, sino que no quisieron prestarle obedecimiento ninguno; cuyos atentados los autorizan con nombre del protector; amagando con él en todos casos y a toda clase de personas; de lo cual se deduce sin violencia que la perversidad de aquella dimana de la irrita y viciosa protectoría que tienen, no siendo despropósito asegurar de que casi se declaran ya, particularmente los de Opodepe, para decir que no reconocen otra autoridad más que la de Gándara ${ }^{39}$.

En la denuncia anónima contra Gándara subyacía una idea clara: en Sonora las cosas habían marchado bien hasta antes de contar con los protectores de in$\operatorname{dios}^{40}$. Después de ese parteaguas, el poblamiento español en Sonora peligra-

38 Un pasaje del anónimo podría dar la pauta para asignar la autoría de dicho documento a fray Luis Romero. Se trata de una alusión del autor a la obligación de respetar a las autoridades constituidas y a sus legítimos mandatos: «La sagrada escritura y los derechos civil y canónico no solamente nos mandan y estrechan a obedecer, respetar y venerar a las legítimas autoridades de la tierra, sino que nos enseñan por aquella sentencia, per me regen regnan, y otras muchas citadas en los libros sagrados, de que su poder y dominio procede de Dios, y que como tal es inviolable y absoluto en nosotros; por cuyo santo principio es consiguiente estamos sujetos a las superioridades y les debemos guardar todo el respeto y veneración que a cada uno corresponda según su representación». Anónimo contra Juan de Gándara por corromper a los indios de Sonora, 1819, AGN, Tierras, volumen 100, f. 481v. Este pasaje sintetiza precisamente la política adoptada por los franciscanos de la provincia de Xalisco (a cargo de las misiones de la opatería) en el contexto de la insurgencia, y retoma las palabras que en repetidas ocasiones transmitieron los encargados de dicha provincia a sus religiosos. Al respecto, véase De la Torre Curiel, 18/1 (Guadalajara, enero-junio 2008): 281-302. La hipótesis de fray Luis Romero se refuerza además por los recientes conflictos que habían enfrentado seriamente a dicho misionero con Juan de Gándara desde principios de 1819.

39 Anónimo contra Juan de Gándara, 11 de febrero de 1819, AGN, Indios, volumen 100, ff. 478-482. La cita está tomada del folio 482.

40 «La provincia de Sonora, por una general costumbre establecida y observada desde tiempos inmemoriales ha recurrido siempre en las necesidades de operarios, ya para las minas, cosecha de mieles, ejercicios de labores y otros tráficos [...] a los pueblos de indios pagando a estos sus jornales acostumbrados, y muchas veces con aumento de ellos». Anónimo contra Juan de Gándara, 11 de febrero de 1819, AGN, Indios, volumen 100, f. 478. 
ba, pues la sociedad entre este procurador y los ópatas, «con notoria injusticia de particulares españoles, sólo ha tratado de sacar avante a los indios en reclamos de éstos con los primeros». Contra todas las reglas de la buena política, y en consonancia con "sus pasiones y espíritu díscolo», Gándara había abierto la puerta de la irreligiosidad y demás vicios entre los indios, quienes se encontraban altivos y desafiantes como nunca. Finalmente, el temor de la rebelión abierta ante este estado de cosas mandaba una señal que esperaba encontrar una respuesta positiva en el contexto de la política contrainsurgente; después de todo, concluía el anónimo, lo peor era dejar que las cosas siguieran su curso natural:

... es susceptible de que los indios afirmándose más con el transcurso del tiempo en las pervertidas costumbres y errores a que les ha dado lugar una protección llena de excesos, de abusos y de pasiones, se llegaran a concebir superiores no solo a los españoles como ya algunos así lo entienden, sino también a declararse en una semi anarquía negando la obediencia a los magistrados políticos y eclesiásticos [...] por lo que sería indispensable recurrir a la fuerza ${ }^{41}$.

Estudios recientes han demostrado que, a diferencia de lo que sugerían estos alegatos, la actitud insumisa, en ocasiones desafiante, que los grupos indígenas del norte de la Nueva España habían adoptado hacia fines del periodo colonial, pasaba más bien por el esfuerzo propio de renegociar los términos en que se daba su inserción en las sociedades fronterizas ${ }^{42}$. En este sentido, la relación entre Gándara y los ópatas se derivaba de un tácito contrato de reciprocidad, el cual comenzaba a desplazar al antiguo "pacto colonial» que empezaba a desmembrarse conforme el régimen misional tocaba a su fin ${ }^{43}$.

Los contextos que rodeaban a esta escritura hablaban no de la simple sumisión o subordinación de los indios a un vecino de recursos; sino de la operación de un principio de suficiencia y reciprocidad que operaba en beneficio de protector y protegidos, pero que, al mismo tiempo, marginaba al resto de los vecinos de la participación de las ventajas de este nuevo pacto. Es probable que el engranaje de estas nuevas sociabilidades no fuera ajeno a las autoridades virreinales, pues entendían que la cercanía entre Gándara y los ópatas le granjeara a éste cierta simpatía entre sus representados, y a la vez alimentara la animadversión de otros vecinos ${ }^{44}$.

41 Anónimo contra Juan de Gándara, 11 de febrero de 1819, AGN, Indios, volumen 100, f. 482 .

42 Cfr. Radding, 1997. Deeds, 2003.

43 Cynthia Radding ha empleado este término para referirse al proceso mediante el cual los indios de misión negociaron su subordinación a la Corona y a la Iglesia a cambio de protección y asistencia. Radding, 1999: 116-135.

$44 \mathrm{Al}$ menos esta es la idea que se desprende de las conclusiones del fiscal protector de na- 


\section{LOS BENEFICIOS DEL PACTO: DOS EJEMPLOS}

Que el vínculo creado a raíz de la representación legal de los ópatas redituó importantes frutos para ambas partes queda claro mediante los dos ejemplos siguientes. El primero de ellos es el conflicto por tierras entre los indios de Opodepe y Tuape (visita de Cucurpe), denunciado ante la audiencia de Guadalajara en $1817^{45}$. La participación de los ópatas al lado de la familia Gándara en las revueltas políticas posteriores a la creación del estado de Sonora ofrece el segundo punto de referencia. Veamos las líneas generales del primer caso.

Existía en los límites entre Opodepe y Tuape un paraje llamado Merisichi: una franja de fértiles tierras de cien cordeles de largo por catorce de ancho, cuya posesión se disputaban ambos pueblos. Como dicho paraje estaba ocupado en ese tiempo por los indios de Tuape, los de Opodepe denunciaban ese hecho como un caso de despojo. Ambos pueblos alegaban la posesión de dicho sitio «desde tiempo inmemorial» y pedían el reconocimiento de las medidas que cada quien exhibía para sustentar sus reclamos. Los de Opodepe decían que ese terreno había sido de su pueblo todo el tiempo, pero que, habiéndose visto imposibilitados para ocuparlo hacía varios años, el terreno había sido prestado a los de Tuape, quienes fincaban sus reclamos en esa ocupación. Como en la fecha del proceso, los de Opodepe decían que estaba su pueblo «con crecido número de indios» y «escasez de terrenos», pedían que se reconociera su derecho de posesión en Merisichi.

Por estas razones, en junio de 1817, el gobernador indígena de Opodepe, José Vázquez, presentó la respectiva denuncia ante el teniente de justicia de Cucurpe, Fernando Grande. Vázquez exponía su reclamo sobre las tierras de Merisichi y acompañaba su alegato con unos documentos donde constaban las medidas del pueblo de Opodepe. Sin embargo, además de desestimar los reclamos de los de Opodepe, Grande se tomó la libertad de arrancar del expediente

turales, quien recomendó al virrey que no diera crédito a esta denuncia, en parte porque las $L e$ yes de Indias indicaban que no se recibieran anónimos que dañaran el honor y los bienes de las personas a partir de deseos de venganza u otros rencores (Ley XLIV, título III, libro III de la Recopilación). Pero, sobre todo, la opinión del fiscal se basaba en que las acusaciones contra Gándara parecían «por su naturaleza increíbles especialmente cuando ese protector no tiene jurisdicción alguna como sucede con los de su clase y por lo mismo se reducen sus gestiones a presentarse a nombre de los Naturales a los magistrados y jueces que han de oír a los sujetos contra quienes se dirigen las quejas». El fiscal protector de naturales al virrey sobre las denuncias contra Juan de Gándara, México, 22 de septiembre de 1819, AGN, Indios, volumen 100, f. 485 .

45 Instancia promovida por los indios de Opodepe contra los de Tuape sobre posesión de terrenos, ARAG, Ramo Civil, 424-1-6888. 
los testimonios de las medidas de Opodepe y entregarlas a fray Fernando Madueño, misionero de Cucurpe (cabecera de Tuape). Los quejosos interpretaron este hecho como una prueba de que el teniente de justicia de Cucurpe y aquel misionero actuaban de común acuerdo para defender la usurpación de los indios de Tuape, por lo que, enseguida, promovieron nuevas instancias ahora ante el intendente de Sonora para recuperar las tierras de Merisichi y para denunciar al teniente y al misionero de Cucurpe.

Enterado el intendente Antonio Cordero de este asunto, determinó en agosto de 1817 dar comisión a Severino Varela, vecino de Opodepe (residente en El Realito), para que hiciera averiguaciones al respecto de los dos puntos de la denuncia. Sin embargo, tal objetivo no pudo cumplirse debido a la poca colaboración de los interesados, lo que llevó a Varela a renunciar a su comisión.

En diciembre de 1817, el intendente Cordero nombró a Ignacio Elías González, comandante de la compañía de pimas de Tubac, como nuevo comisionado para esta causa. En esta etapa, los protagonistas de la disputa por las tierras limítrofes entre Opodepe y Tuape serían los protectores de indios de ambos pueblos. Confiando quizá en la forma en que el padre Madueño llevaba el asunto en Tuape, el protector de indios de aquel distrito, don Tomás de Escalante, se limitó a enviar un oficio al intendente en el cual decía tener en sus manos una copia de las medidas del fundo legal de Tuape, en donde se advertía que le hacían falta 78 cordeles para completar su dotación, pues sólo se le habían entregado 322 de los 400 cordeles correspondientes ${ }^{46}$.

Juan de Gándara, el protector de Opodepe, en cambio, tomaba una estrategia distinta. A los pocos días de que el comisionado Elías González llegara a Tuape, Gándara se presentó con un oficio en el que pedía que el comisionado pasara a reconocer las medidas del pueblo de Opodepe según constaba en un testimonio que recientemente había «encontrado en un archivo». Elías González tenía sobrados motivos para sospechar de la premura con que Gándara urgía estas medidas, por lo que se excusó de atenderlo, alegando que no podía realizarlas si no estaba presente el protector de los indios de Tuape.

Tras analizar esta situación y algunos otros testimonios, Elías González llegaba a una conclusión desfavorable para Opodepe. Por una plática con el gobernador de Opodepe se había convencido de que aquellos indios no se conformaban con recibir tierras por cualquier rumbo de su pueblo, sino que estaban interesados en Merisichi en particular. Los reclamos de posesión inmemorial podían desestimarse porque no mostraban ningún documento que probara

46 Entregar Merisichi a los de Tuape completaría la dotación de este pueblo y resolvería el problema de límites, sugería Escalante. Oficio de Tomás de Escalante al intendente Antonio Cordero, Arispe, 17 de diciembre de 1817, ARAG, Ramo Civil, 424-1-6888, ff. 44-45. 
su pretensión, pues los papeles que tenían eran copias simples a las que no se podía dar crédito. Lo único que era cierto, concluía Elías González en un informe al intendente de Sonora, era que los indios de Opodepe,

\begin{abstract}
... de tiempo inmemorial jamás, ni nunca han hecho uso de aquel terreno... ni para rancho, ni siembras, por cuya causa empezaron de 20 años a esta parte a introducirse en dicho paraje algunos vecinos, y con mil afanes, y crecido trabajo personal, y desmontes terribles, empezaron a sembrar poniendo saca de agua. Visto esto por éstos indios..., aparentando ser de ellos aquel terreno les empezaron a cobrar arriendo [a los vecinos]..., después de esto comenzaron los indios de Tuape de veinte años a esta parte... mas arriba a desmontar tierras y cultivarlas con inmenso trabajo y cuando ya estaban abiertas dichas labores, y en cultivo, comenzaron a quererlos quitar de allí, no con el fin de sembrarlas ellos, pues jamás lo han hecho, y sí para tener el lucro después de derramado su sudor, transportar a los vecinos dichas tierras con arriendo anual ${ }^{47}$.
\end{abstract}

La conclusión del comisionado Elías González, ratificada luego por el intendente, era desestimar los reclamos y medidas presentadas por los quejosos, procediendo a realizar nuevas medidas para completar el fundo legal de cada pueblo (cuatro leguas). Gándara se opuso a tal resolución y consiguió dar largas al asunto, exigiendo que las medidas se realizaran de acuerdo a los documentos que él había «encontrado». Elías González dio por finalizada su comisión y en abril de 1818 llegó un nuevo comisionado, José Esteban, capitán del presidio de Bacoachi. Esteban logró reunir a Gándara y al protector de Tuape, Fernando Lino de Cárdenas (quien representaba a Tomás de Escalante), en mayo de 1818 para proceder a las medidas de ambos pueblos en los términos que solicitaba Gándara. Gracias a la astucia del protector de Opodepe, las nuevas medidas favorecieron a sus protegidos, pues la solución a este conflicto fue la asignación de Merisichi a Opodepe. En este punto, el conflicto tomó un giro por demás inesperado, pues reconociéndose ahora la posesión de Opodepe sobre Merisichi, Gándara hizo «donación» de 41 cordeles de aquella tierra al pueblo de Tuape, conservando sólo 59 cordeles para Opodepe ${ }^{48}$. El objetivo de la donación, se comprendería más tarde, era pedir que se completara el fundo legal de Opodepe con las tierras vecinas a El Realito, real minero cuyos vecinos vivían principalmente de los productos de las tierras que arrendaban a los opodepetanos.

A pesar de que no contamos con noticias que indiquen la resolución final de este conflicto, sabemos, en cambio, que el hecho de que la balanza se inclinara hacia el lado de Opodepe precipitó airadas reacciones desde diversos

47 Ignacio Elías González al intendente Antonio Cordero, Opodepe, 24 de diciembre 1817, ARAG, Ramo Civil, 424-1-6888, f. 69.

48 Instancia promovida por los indios de Opodepe contra los de Tuape sobre posesión de terrenos, ARAG, Ramo Civil, 424-1-6888, ff. 120-140. 
frentes. En un intento por revertir el curso que tomaba el conflicto de límites entre Tuape y Opodepe, el teniente de justicia de Cucurpe, Fernando Grande, acusó al pueblo de Opodepe y a su protector, Juan de Gándara, por el delito de infidencia en marzo de $1818^{49}$. Presentar a los opodepetanos como insurgentes en medio de las luchas de independencia en la Nueva España parecía oportuno para los de Tuape, pero a nadie se ocultaba que este cargo nacía de los conflictos por tierras entre ambos pueblos ${ }^{50}$. La prueba del delito, argumentaba Fernando Grande, consistía en haberse descubierto «una construcción de arcos y lanzas que se intenta hacer en el pueblo de Opodepe», responsabilizando a Juan de Gándara como orquestador de este sospechoso armamento de los indios de Opodepe ${ }^{51}$.

El intendente de Sonora sabía que esta demanda se relacionaba con el conflicto por Merisichi, por lo que pidió al comisionado José Esteban que se ocupara también de este asunto al tiempo que procedía a las medidas de Opodepe y Tuape. De las averiguaciones realizadas por Esteban se supo que el gobernador opodepetano había enviado dos indios a las inmediaciones de Cucurpe a cortar palos de mora para fabricar arcos y lanzas que serían entregados a Juan de Gándara; varios testimonios adicionales confirmaban estos hechos y revelaban el recelo que los vecinos del distrito de Cucurpe tenían sobre el «uso indebido» que los de Opodepe pudieran dar a esas armas ${ }^{52}$.

Otros testimonios, sin embargo, aclaraban que era verdad que Gándara había solicitado al misionero de Opodepe, fray Luis Romero, suficiente número de arcos y lanzas; no obstante, ello tenía como fin armar a los indios que tenía a su servicio en su rancho de Santa Rita (Ures) para hacer frente a los seris. El

49 Defensa de Juan de Gándara sobre la acusación de infidencia contra los indios de Opodepe, San Miguel de Ures, 24 de julio de 1818, ARAG, Ramo Civil, 264-5-3600.

50 En 1822 recordaba el fiscal de la audiencia de Guadalajara este caso como una conspiración entre el teniente Fernando Grande y el padre Madueño contra los de Opodepe. «Acerca de la indicada acusación, fraguada por el citado teniente y el padre fray Fernando Madueño con el fin de interrumpir la secuela del asunto sobre tierras, conoció este superior tribunal [y se convenció] que la calumnia e impostura del acusador no pudo perjudicar a los perseguidos indios de Opodepe, que la conducta de éstos era irreprensible y notorio su patriotismo». ARAG, Ramo Civil, 424-1-6888, f. 190.

51 Diligencias practicadas a consecuencia de representación del Teniente de Justicia de Cucurpe sobre que los indios de Opodepe habian provisión extraordinaria de arcos y flechas. Fernando Grande a Antonio Cordero, Cucurpe, 30 de marzo de 1818, ARAG, Ramo Civil, 427-11-6947, ff. 3-4.

52 Diligencias practicadas a consecuencia de representación del Teniente de Justicia de Cucurpe sobre que los indios de Opodepe habian provisión extraordinaria de arcos y flechas. Interrogatorio de Francisco Salazar, El Realito de Opodepe, 20 de abril de 1818, ARAG, Ramo Civil, 427-11-6947, f. 28. 
padre Romero, junto con el comerciante Ramón Agudo y el gobernador de Opodepe José Vázquez, decidieron regalar este armamento al protector Gándara, contribuyendo el misionero con el bastimento de los cortadores de madera, el gobernador con dos hijos de misión para ir a traer la madera y el comerciante Agudo con las mulas en que se transportarían los palos ${ }^{53}$.

En vista de estas evidencias, la opinión del comisionado Elías González era que no había razones para temer una agresión de los indios de Opodepe contra Cucurpe. Así lo informó al intendente Antonio Cordero, quien al comentar este asunto con Alejo García Conde, comandante general de las Provincias Internas, no dudaba en señalar dos responsables de estos problemas. Al entrar a servir su oficio de intendente, decía Cordero, había encontrado «a los indios de Tuape y Opodepe empeñados en un litigio sobre linderos»; al poco tiempo se había dado cuenta que los misioneros de ambos pueblos «eran los que fomentaban la discordia», motivando a que gobernadores y protectores tomaran en sus manos la defensa de la postura de los misioneros. Por ello, pensaba Cordero, el objeto de esta nueva denuncia era «sorprender al gobierno y hacerlo instrumento de una ruin venganza», lo cual se consumaría de no pedir al comisario de misiones de Xalisco la remoción de ambos misioneros ${ }^{54}$.

Los episodios aquí abordados describen enfrentamientos entre pueblos de una misma etnia, entre intereses conflictivos de vecinos y pobladores indígenas, y entre comunidades y sus autoridades civiles y eclesiásticas, pero al mismo tiempo confirman dos procesos de cambio que caracterizan la vida de los pueblos de indios en los comienzos del siglo XIX. De una parte, resulta claro que para el siglo XIX el eje integrador de la vida socioeconómica de pueblos como los de la Opatería no era ya la misión, sino los conjuntos agroganaderos de un grupo de prominentes rancheros y comerciantes que comenzaban a destacar en este periodo. En el área de Opodepe, quien asumió dicho papel fue Juan de Gándara, personaje que aparece en todos los casos arriba mencionados litigando a favor del común del pueblo, dando trabajo a los opodepes en sus ranchos, y dotando de armamento a los indios para asegurar sus propios intereses y los de sus protegidos.

53 Diligencias practicadas a consecuencia de representación del Teniente de Justicia de Cucurpe sobre que los indios de Opodepe habian provisión extraordinaria de arcos y flechas, ARAG, Ramo Civil, 427-11-6947, ff. 18-40.

54 Diligencias practicadas a consecuencia de representación del Teniente de Justicia de Cucurpe sobre que los indios de Opodepe habian provisión extraordinaria de arcos y flechas, Antonio Cordero al Mariscal de Campo Don Alejo García Conde, Durango, 30 de julio de 1818, ARAG, Ramo Civil, 427-11-6947, ff. 46-48. Las malas noticias para el intendente Cordero era que, por esas fechas, el padre Fernando Madueño era nombrado por la provincia franciscana de Xalisco comisario de misiones de Sonora. 
Por otro lado, estudios recientes han mostrado que en los pueblos de indios, durante las etapas de formación republicana, las expresiones colectivas de protesta, violencia o cooperación política con otros actores sociales nacían de las formas en que, en el interior de las comunidades, se alcanzaban consensos en cuanto a las diferentes agendas que involucraban los intereses de la colectividad ${ }^{55}$. En los casos aquí estudiados, la cambiante actitud del pueblo de Opodepe hacia su misionero - y las durables alianzas con la familia Gándara- parece ceñirse a esta nueva forma de entender las negociaciones políticas del siglo XIX. Sin embargo, es necesario recordar lo que con frecuencia se ha obviado en estos análisis de historia política. El cemento que mantenía en pie estas alianzas tenía expresiones materiales manifiestas en los beneficios que los pueblos obtenían de sus interlocutores. Para las primeras décadas del siglo XIX, las misiones de la Opatería no podían ofrecer un modelo alternativo de seguridad y suficiencia laboral. En este contexto, la participación de los ópatas durante las décadas de 1840 y 1850 al lado de Manuel María Gándara en los enfrentamientos armados contra José Urrea, se explica a partir de los contratos no escritos establecidos por la familia Gándara y los habitantes de la Opatería desde el periodo colonial. Derrotados los Gándara en la batalla por el control del estado de Sonora, el gobernador José Urrea conocía la dificultad de atraer para sí la lealtad de los ópatas, por lo cual, la salida más práctica para su gobierno consistió en ofrecer en 1842 el indulto a los colaboradores de Gándara y enviarlos a combatir a los apaches en la frontera oriental del estado para «purificar sus culpas» ${ }^{56}$. Desdeñando este perdón, los ópatas y pimas leales a Juan Tánori, capitán general de dichas naciones, permanecieron en pie de guerra por varios años sin permitir que el gobierno de Urrea tuviera el control de los pueblos de la sierra. Para 1859, Tánori y sus seguidores seguían manifestando su rechazo al gobierno estatal, desconociendo mediante el Plan de Tepupa al gobernador Pesqueira y apoyando a Manuel María Gándara al frente del ejecutivo estatal. Aunque la muerte de Juan Tánori ese mismo año frenó esta etapa de inconformidades de los ópatas, su identificación con las familias locales continuaría todavía durante la época de

55 Mallon, 1995: 319. Guardino, 1996: 147-168.

56 El decreto establecía que «todos los indígenas de los pueblos de ópatas y pimas que han abrazado y seguido la revolución llamada de D[on] Juan [Bautista] Gándara quedan amnistiados y en consecuencia libres de toda responsabilidad con tal de que se presenten dentro de ocho días de la publicación de este decreto en sus pueblos y de que precisamente marchen a la Campaña que va a salir contra el Apache. Esta jornada los purificará de la culpa que contrajeron en su deferencia y restablecerán el crédito de valientes y subordinados que siempre han disfrutado». Decreto del Gobernador José Urrea sobre amnistía a seguidores de Juan Bautista Gándara, Hermosillo, 8 de agosto de 1842, BL, MSS xff F1203.P5, n. ${ }^{\circ} 616$ VAULT. 
la intervención francesa bajo el liderazgo de nuevos miembros de la familia Tánori ${ }^{57}$.

Determinar si el vínculo carismático era más fuerte que los mecanismos de negociación interna de las comunidades es tarea que escapa a los límites de este estudio; sin embargo, lo que queda claro es que en estas regiones los vínculos entre los personajes prominentes de la élite sonorense y las comunidades indígenas se consolidaron al avanzar el siglo XIX. No se puede entender, por ejemplo, la guerra de facciones arriba citada sin considerar las raíces históricas que permitieron que la familia Gándara cultivara por varias décadas múltiples nexos de ayuda y reciprocidad; sin este contexto no se explica la razón por la cual los pueblos indígenas del centro de Sonora apoyaran decididamente a los Gándara, una de las «tres redes de parentesco que dominaron la escena política en Sonora», en las guerras por el poder político que caracterizaron a ese estado durante los años posteriores a $1831^{58}$.

\section{BIBLIOGRAFÍA}

Almada, Francisco R., Diccionario de Historia, Geografía y Biografía Sonorenses, Hermosillo, Gobierno del Estado de Sonora, 1983.

Almada Bay, Ignacio, Breve historia de Sonora, México, Fondo de Cultura Económica, 2000.

Annino, Antonio, «Soberanías en lucha», Antonio Annino, Luis Castro Leiva y François Xavier-Guerra (eds.), De los Imperios a las Naciones: Iberoamérica, Zaragoza, IberCaja, 1994: 229-253.

Annino, Antonio, "Cádiz y la revolución territorial de los pueblos mexicanos, 1812-1821», Antonio Annino (ed.), Historia de las elecciones en Iberoamérica, siglo XIX, Buenos Aires, Fondo de Cultura Económica, 1995a: 177-226.

Annino, Antonio, «Prácticas criollas y liberalismo en la crisis del espacio urbano colonial», Enrique Montalvo (coord.), El águila bifronte, poder y liberalismo en México, México, Instituto Nacional de Antropología e Historia, 1995b: 17-63.

Ayala, Manuel Josef de, Diccionario de Gobierno y Legislación de Indias, tomo XII, Madrid, Agencia Española de Cooperación Internacional, Ediciones de Cultura Hispánica, 1995.

57 Almada, 1983: 679-680.

58 En 1831, el Estado de Occidente se separó en los estados independientes de Sonora y Sinaloa. A partir de ese año, y hasta 1891, en que se consolida el régimen porfirista en Sonora, se vivieron en dicho estado largos periodos de guerras de facciones para controlar el poder político. Almada Bay, 2000: 124-134. 
Bayle, Constantino, El protector de indios, Sevilla, Escuela de Estudios Hispanoamericanos, 1945.

Burke, Peter, ¿Qué es la Historia Cultural?, Barcelona, Paidós, 2006.

Cutter, Charles R., The Protector de Indios in Colonial New Mexico, 1659-1821, Albuquerque, University of New Mexico Press, 1986.

De Castro, Concepción, La revolución liberal y los municipios españoles, Madrid, Alianza Editorial, 1979.

Deeds, Susan, Defiance and Deference in Mexico's Colonial North. Indians Under Spanish Rule in Nueva Vizcaya, Austin, University of Texas Press, 2003.

De la Torre Curiel, José Refugio, «Comerciantes, precios y salarios en Sonora en el periodo colonial tardío. Caracterización de un circuito comercial cautivo», Historia Mexicana, LVIII/2 (230) (México D. F., 2008): 595-656.

De la Torre Curiel, José Refugio, «Los franciscanos y la retórica de la subordinación a principios del siglo XIX», Revista Jurídica Jalisciense, 18/1 (Guadalajara, enerojunio 2008): 281-302.

De la Torre Curiel, José Refugio, «Enemigos encubiertos: bandas pluriétnicas y estado de alerta en la frontera sonorense a finales del siglo XVIII», Takwá. Revista de historia, 14 (Guadalajara, 2008): 11-31.

De la Torre Curiel, José Refugio, «Decline and Renaissance Amidst the Crisis: The Transformation of Sonora's Mission Structures in the Late Colonial Period», Colonial Latin American Review, 18/1 (Londres, 2009): 51-73.

Escobar Ohmstede, Antonio, «Los Ayuntamientos y los pueblos Indios en la Sierra Huasteca: conflictos entre nuevos y viejos actores, 1812-1840», Leticia Reina (coord.), La reindianización de América, siglo XIX, México, Siglo XXI- CIESAS, 1997: 294-316.

Guardino, Peter, Peasants, Politics, and the Formation of Mexico's National State, Stanford, Stanford University Press, 1996.

Guedea, Virginia, «El pueblo de México y las elecciones de 1812», Regina Hernández (comp.), La ciudad de México en la primera mitad del siglo XIX, tomo II, México, Instituto de Investigaciones José María Luis Mora, 1994: 125-165.

Hinton, Thomas B., «Southern Periphery: West», Alfonso Ortiz (ed.), Handbook of North American Indians. The Southwest, volumen 10, Washington, Smithsonian Institution, 1983: 315-328.

León Pinelo, Antonio de y Solórzano Pereyra, Juan de, Recopilación de leyes de los reynos de las indias, tomo II, 4. a impresión, Madrid, Viuda de D. Joaquín Ibarra, 1791. 
Mallon, Florencia, Peasant and Nation. The Making of Postcolonial Mexico and Peru, Berkeley, University of California Press, 1995.

Nentuig, Juan, El rudo ensayo. Descripción geográfica, natural y curiosa de la provincia de Sonora, 1764, México, Instituto Nacional de Antropología e Historia, 1977.

Ortelli, Sara, Trama de una guerra conveniente: Nueva Vizcaya y la sombra de los apaches (1748-1790), México, El Colegio de México, 2007.

Romanelli, Raffaele, «Sistemas electorales y estructuras sociales. El siglo XIX europeo», Salvador Forner (coord.), Democracia, elecciones y modernización en Europa, siglos XIX y XX, Madrid, Cátedra, 1997: 23-46.

Radding, Cynthia, Wandering Peoples: Colonialism, Ethnic Spaces, and Ecological Frontiers in Northwestern Mexico, 1700-1850, Durham, Duke University Press, 1997.

Radding, Cynthia, «Cultural Boundaries between Adaptation and Defiance: The Mission Communities of Northwestern New Spain», Nicholas Griffiths (ed.), Spiritual Encounters. Interactions between Christianity and Native Religions in Colonial America, Lincoln, University of Nebraska Press, 1999: 116-135.

Sauer, Carl, Aboriginal Population of Northwestern Mexico, Berkeley, University of California Press, 1935.

Suñe Blanco, Beatriz, «Evolución de la figura del protector de indios en la frontera norte de Nueva España», Antonio Gutiérrez Escudero y María Luisa Laviana Cuetos (coords.), Estudios sobre América: siglos XVI-XX, Sevilla, Asociación Española de Americanistas, 2005: 727-743.

Vidargas, Juan Domingo, «Sonora y Sinaloa como provincias independientes y como Estado interno de Occidente: 1821-1830», Sergio Ortega Noriega e Ignacio del Río (coords.), Tres siglos de historia sonorense (1530-1830), México, Universidad Nacional Autónoma de México, 1993: 423-466.

Zúñiga, Ignacio, Rápida ojeada al estado de Sonora. Dirigida y dedicada al Supremo Gobierno de la Nación, México, Imprenta de Juan Ojeda, 1835.

Recibido el 13 de agosto de 2009

Aprobado el 19 de noviembre de 2009 


\section{A FRONTIER PATRONAGE: THE PROTECTOR OF INDIANS, JUAN DE GÁNDARA, AND THE OPATAS OF OPODEPE (SONORA) AT THE BEGINNING OF THE $19^{\text {th }}$ CENTURY}

This study analyses the relations between the protector of Indians, Juan de Gándara and the villages of Sonora under his protection. This relationship is understood here as an effective mechanism of social reorganisation which allowed the Indians to confront the dismantling of their communities in the context of the collapse of the missions. At the same time, the relationship is identified as fundamental to the consolidation of the political capital of the new regional elites. Eventually this response would contribute decisively to the shaping of the political factions that dominated the scene in Sonora during the middle of the $19^{\text {th }}$ century, whose existence cannot be explained without this type of alliance.

KEY WORDS: Sonora, Opatas, protectors of Indians, breach of confidence, lands. 